\title{
Knowledge management as a support for supply chain logistics planning in pandemic cases
}

Carlos Alberto Schettini Pinto ${ }^{1}$

${ }^{1}$ Postgraduate Course in Logistics and Supply Chain Management, Getulio Vargas Foundation, Rio de Janeiro, Brazil.

How to cite: Pinto, C.A.S. (2020), "Knowledge management as a support for supply chain logistics planning in pandemic cases", Brazilian Journal of Operations \& Production Management, Vol. 17, No. 03, e2020970. https://doi.org/10.14488/BJOPM.2020.033

\section{ABSTRACT}

Goal: This study presents how the knowledge management can be an excellent ally to logistics for planning the supply chain in actions in cases of pandemic.

Design / Methodology / Approach: The present study was based on a bibliographic review sought in the main existing databases. From there, it was possible to obtain subsidies to support the proposal of this work.

Results: The results showed that a correct application of knowledge management can assist in logistical planning in a very effective way, reducing gaps and shortages, providing very effective actions to mitigate the main obstacles that a pandemic can generate.

Limitations of the investigation: The most important limitation in this study was the fact that the COVID-19 pandemic is still very active and logistics operations do not yet have effective and consolidated data to bring even more reliable results.

Practical implications: According to the conclusions obtained, governmental organizations, at their three levels (municipal, state and federal) should focus on creating public policies that mitigate the problems of supplying of the various matrices of inputs and products.

Originality / Value: The main contribution of the research lies in the opportunity to present a management component to assist the logistical demands that occur in a pandemic environment.

Keywords: Knowledge management; Supply chain management; Logistics; Pandemic.

\section{INTRODUCTION}

When we speak of a pandemic, our temporal memory brings us to the most recent case, which is COVID-19 (Coronavirus Disease 2019). This is an infectious disease caused by the coronavirus of severe acute respiratory syndrome 2 (SARS-CoV-2) that was initially identified on December 1, 2019, in Wuhan, Hubel province, in the People's Republic of China.

On February 3, 2020, through Ministry of Health Ordinance $n^{\circ}$. 188, a Public Health Emergency was declared in Brazil (Brasil, 2020a). It was considered a pandemic by the World Health Organization on March 11. It is present in 187 countries and territories, as reported by the United Nations Statistics Division. (United Nations, 2020).

In early February, Brazil had the first case confirmed. On February 9, 34 Brazilians living in Wuhan were repatriated. On February 26, the first case in the country in the city of São Paulo was confirmed. On March 5, the first internal transmission in the country was recorded. In order to contain the spread of cases and reduce the epidemiological curve, on March 13, the Ministry of Health regulated isolation and quarantine criteria which led states and municipalities to start adopting vertical confinement, seeking to reduce circulation to the 
maximum of people. Subsequently, it determined the closure of shops, malls, stores, etc., which were not of express popular need, such as markets, pharmacies, service stations, among others. On March 17, the first death in national territory from COVID-19 occurs.

At the same time, countless countries have closed their borders, reducing logistical outflow, causing immense queues. This impact ended up causing a delay in the delivery of medicines, food, supplies, parts and equipment, causing a retardment in the production of items, including health equipment. At the same time, several brazilian states, in an autonomous and disorderly manner, also adhered to this practice, which caused an imbalance in the national productive logistics. Together, there was a growing international demand for brazilian agribusiness due to the problems caused by COVID in other countries, creating a need for greater flow of national commodities.

Nevertheless, the closure of commercial establishments on the roads hampered the highway logistical flow, since truck drivers could not carry out their meals at existing stops on federal and state highways, nor did they have access to essential services such as tire repair shops, workshops, among others. In order to have a minimum consensus, the Ministry of Infrastructure intervened with the governors of the southern and southeastern regions, calling attention to the possibility of shortages as well as the lack of supplies for the pharmaceutical industries, health equipment and other services. In the air sector, some governors determined the suspension of flights to their states, once again generating the intervention of the Ministry of Infrastructure. With regard to ports, the National Aquatic Transport Agency (ANTAQ) clarified, by means of a note on its portal, that only the Union will be able to determine the closure of port facilities in brazilian states, as well as the suspension in the provision of services. (Brasil, 2020b).

As we realized, knowledge is fundamental in all environments and, in a crisis environment, it can be the balance between life and death. One of the main actors in this context is logistics. There is no certainty as to the origin of the name, being attributed to the French logger - hosting or hosting; or Greek logos - speech, reason and language. However, more specifically, we have the term logistiki which means accounting and financial organization. Anyway, if there is no certainty as to its etymological origin, we can say that its appearance and development stem from the progress of military activities, especially when in a state of conflict. There is no specific date or period to determine its appearance, but its use is perceived before the beginning of the Christian era, passing through the great battles reported in the history of the world, until the present moment, where military doctrine encourages, in any conflict, seek as soon as possible the interruption of supply lines in order to prevent the maintenance of the logistical means of the opposing army. It is important to emphasize that the issue here is not interruption, quite the contrary, it is the continuity of production and its flow in order to meet the entire national territory based on existing demands. It is the continuity of actions when the system, probably collapsed, needs inputs to be able to carry out its life-saving work.

In this diapason, logistics meets a series of specific demands. As previously said, whether in the delivery of inputs for production, or in the disposal of this production, or in the provision of means for equipping fixed or field hospitals. However, we cannot fail to mention that the population does not need to survive and, therefore, the flow of agro-industrial production to wholesale or retail markets is essential, in order to meet the demands that will certainly occur. Another essential input for human survival are medicines, vaccines, laboratory tests, medical and hospital services and the consequent supply of pharmacies and drugstores. The transportation of fuels, food and the deceased are also part of this "war effort", which is a military concept, but which, in times of pandemic, can be seen as the mobilization of means and personnel in order to maintain the continuous flow of products, services and personnel to meet the demands in these areas.

We cannot forget the maintenance of basic infrastructures through the energy, road, sanitary, health and communications systems. It will be these systems that will allow logistics and healthcare to work more efficiently. These systems make it easier and more agile to control displacements, the correct destination of inputs, the maintenance of hospital devices etc.

Globalization ended up generating interdependence of inputs in several countries. Hardly a consumer good is assembled only with materials produced in a single country. In Brazil it is no different and, in the course of the pandemic, we had a high demand, mainly for hospital respirators, N95 masks and alcohol-gel. Due to their shortcomings, several actions ended up 
being implemented aiming to mitigate the existing obstacles where, beer makers and universities changed their routines for the production of alcohol-gel, seamstresses started to sew and sell washable and reusable cloth masks and start-ups created simpler and cheaper models of respirators to meet internal demands. They all ran into the problem of the lack of inputs for greater mass production.

After the passing of this pandemic, it is believed that many actions should be structured or restructured according to the respective cases. Processes must be rethought, suppliers will be reevaluated, among other factors.

In this line of thought, knowledge management emerges, which is recognized as a multidisciplinary area and can be used in all professional fields as a support to its activities, serving, among other things, as a repository of knowledge and practices experienced by different actors and shared collectively or collaboratively in an easily accessible environment. It aims to generate value for the organization, be it from any work area.

For Choo (2006), information, under the conception of modern administration and organizational theory must be understood, as an activity, linked to three diverse and strategic fields: i) Information is strategically used by organizations in business development in the that attends to its changes and adaptations to the external environment; ii) Organizations, through the strategic use of information, can create, organize and process information capable of generating new knowledge, anchoring themselves in learning and; iii) The practice of strategic information authorizes organizations to validate their actions by making rational decisions, which take place in complex environments in the face of conflicting interests, in order to achieve their business objectives.

So, making use of the capacity of the tools and capacities available in knowledge management allows those who plan logistical actions during pandemic events to have valuable information for proposing more effective actions in troubled times.

\title{
LITERATURE REVISION
}

\section{Knowledge Management}

Knowledge Management (KM) can be defined as a

\begin{abstract}
"set of strategies to create, acquire, share and use knowledge assets, as well as establish flows that guarantee the necessary information in the appropriate time and format, in order to assist in the generation of ideas, problem solving and decision making". (Machado Neto, 1998).
\end{abstract}

Krumina et al. (2015) mentions that KM is an integral part of business management that covers all relevant management areas. Thus, it is credible to understand that supply chain management can, and should, have a KM process that allows it to retain relevant and necessary knowledge for its operation in repositories. Calvo-Mora et al. (2015) point out that the main objective of the KM process must be to generate value for the agents that intervene in the process. More broadly, Chang and Lin (2015) understand that if companies are able to effectively manage their knowledge resources, a wide variety of benefits can be reaped, such as better corporate efficiency, effectiveness, innovation and customer service. This is nothing more than what is expected from the supply chain management. When analyzing the implementation of the KM program in Chilean companies, Liberona and Ruiz (2013) state that by promoting and developing KM practices and theories in organizations, increasingly complex networks of knowledge relationships are developed inside and outside the organizational boundaries where a number of tools and collaborative practices known as the Internet, social networks and Web 2.0 stand out.

Terzieva (2014) points out that efficient knowledge management maximizes internal efficiency, profitability and ensures competitive advantage for the organization, which is a sine-quae-non condition for logistics processes. Knowledge comes mainly from group actions and interactions of participants in the research and that, during this process, there is a high level 
of personal and group reflection, always aiming at the design of the next improvement processes, in the description of Mylonakou-Keke (2012).

Al-Ghamdi and Al-Ghamdi (2015) presents the growing identification of the vital role that knowledge plays in defining the identity of contemporary societies and in determining their destinies in a world characterized merely by quality and competitiveness, by scientific and technical revolutions. Trejo et al. (2016) considers that innovation, when improved by the direct action of $\mathrm{KM}$, is a key factor to increase the competitive advantage for companies. So it would be correct to state that, by innovating logistical procedures, we will be contributing to the competitive advantage of distribution channels and, consequently, the productive sectors, since, within a "Win X Win" concept, all parties involved will be positively affected in the scope of the process.

We can highlight the KM project implemented by Volvo Tecnologia, which is described by Johansson et al. (2013), emphasizing that the company identified a mismatch in the knowledge sharing strategies between the employee and the recipient. To remedy this anomaly, the company ranged from common folders and systems where documents were stored in wiki tools, where employees shared their knowledge through articles. A "white paper" has been created, which can be described as a report to be written at the end of a project and which documents important information about the project. This report was stored in a common database allowing great accessibility for other employees.

Jakobsone et al. (2017) state that knowledge sharing is an infinite process, where all parties involved need to be motivated constantly, ensuring that they remain functioning intensively. This stimulus must be deliberately broad and easily accessible. All the actors involved - society, industry, educational institutions, government agencies, researchers - have a cognitive background to interpose their ideas. The construction of knowledge in a collaborative and collective way allows that the chain of ideas allows the emergence of great ideas and solutions. However, it is necessary to have a system manager in order to mediate actions. In this sense, Dalkir (2017, p. 39-43) argues that effective knowledge management requires an organization to identify, generate, acquire, disseminate and capture the benefits of knowledge that provide a strategic advantage for that organization. Probably a Teaching Institution that conducts research on the thematic, supported by government subsidies and organizations that use this knowledge would be the most propitious manager for this type of knowledge, since Universities are commonly disseminators of knowledge. In his book Knowledge Management in Theory and Practice, the author presents us with the knowledge management cycle proposed by Meyer and Zack (1996), which derives from the work on design and development of information products, where it is proposed that research and knowledge about the design of physical products can be extended to the intellectual domain, serving as a basis for a knowledge management cycle, as we can see in Figure 1. In this work, the authors carry out a series of comparisons with the notion of a product platform (the knowledge repository) and the information process platform (the knowledge refinery).

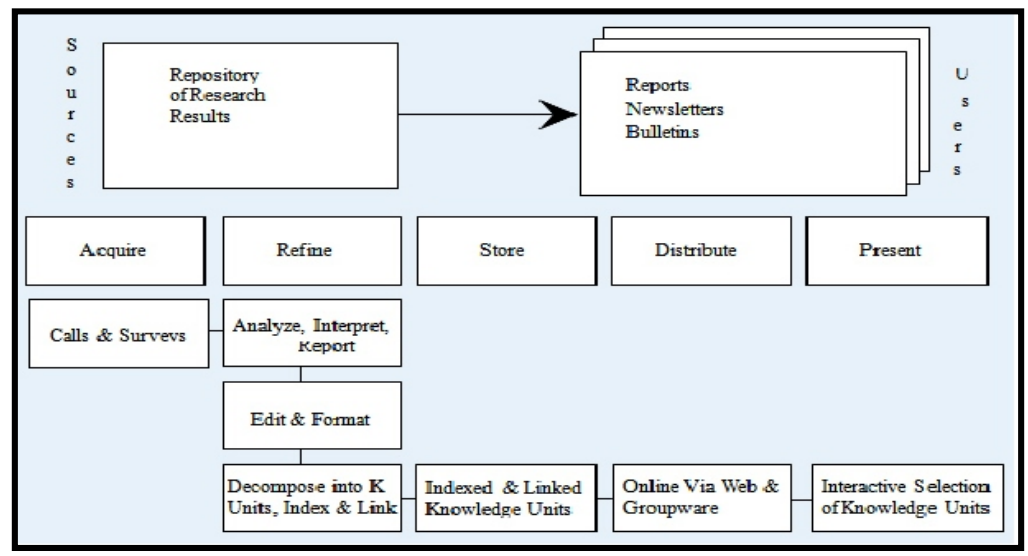

Figure 1. Meyer and Zack cycle (1996).

Source: Adapted from Dalkir, (2017). 
Finally, we could not fail to mention Carvalho (2012, p. 5-6) and the definitions of data, information and knowledge as shown in Figure 2. Data is the record of an occurrence and has no inherent meaning. Information is a set of data with a certain meaning for the system. Knowledge is information that, properly treated, changes the behavior of the system.

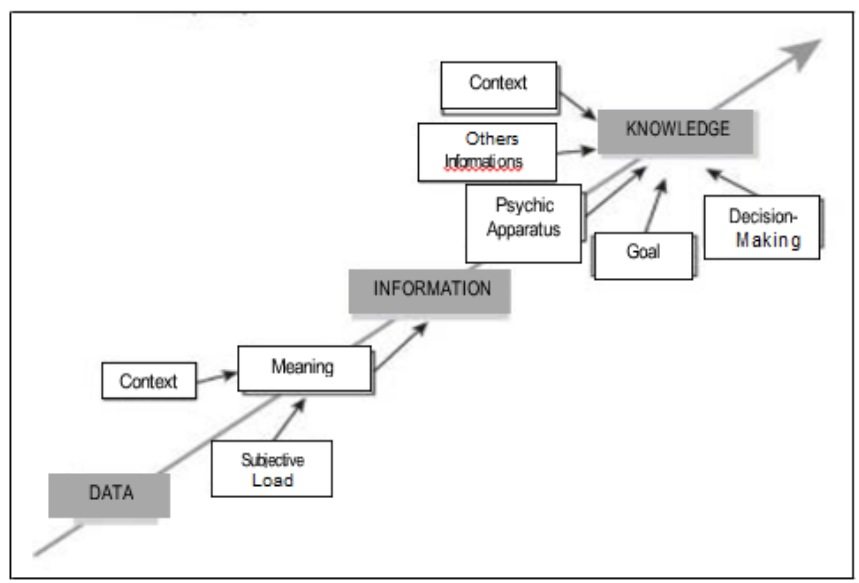

Figure 2: Development of Data in Information and this in Knowledge Source: Adapted from Carvalho (2012)

\section{Supply Chain Management}

Bowersox et al. (2014) believes that Supply Chain Management (SCM) consists of collaboration between companies to boost strategic positioning and improve operational efficiency. When we perceive the information listed in Figure 3, we realize that the flow of information runs through the entire network, from inputs (materials), through processing, until delivery to the final consumer. All of its processes are interconnected, allowing a complete flow of information and actions.

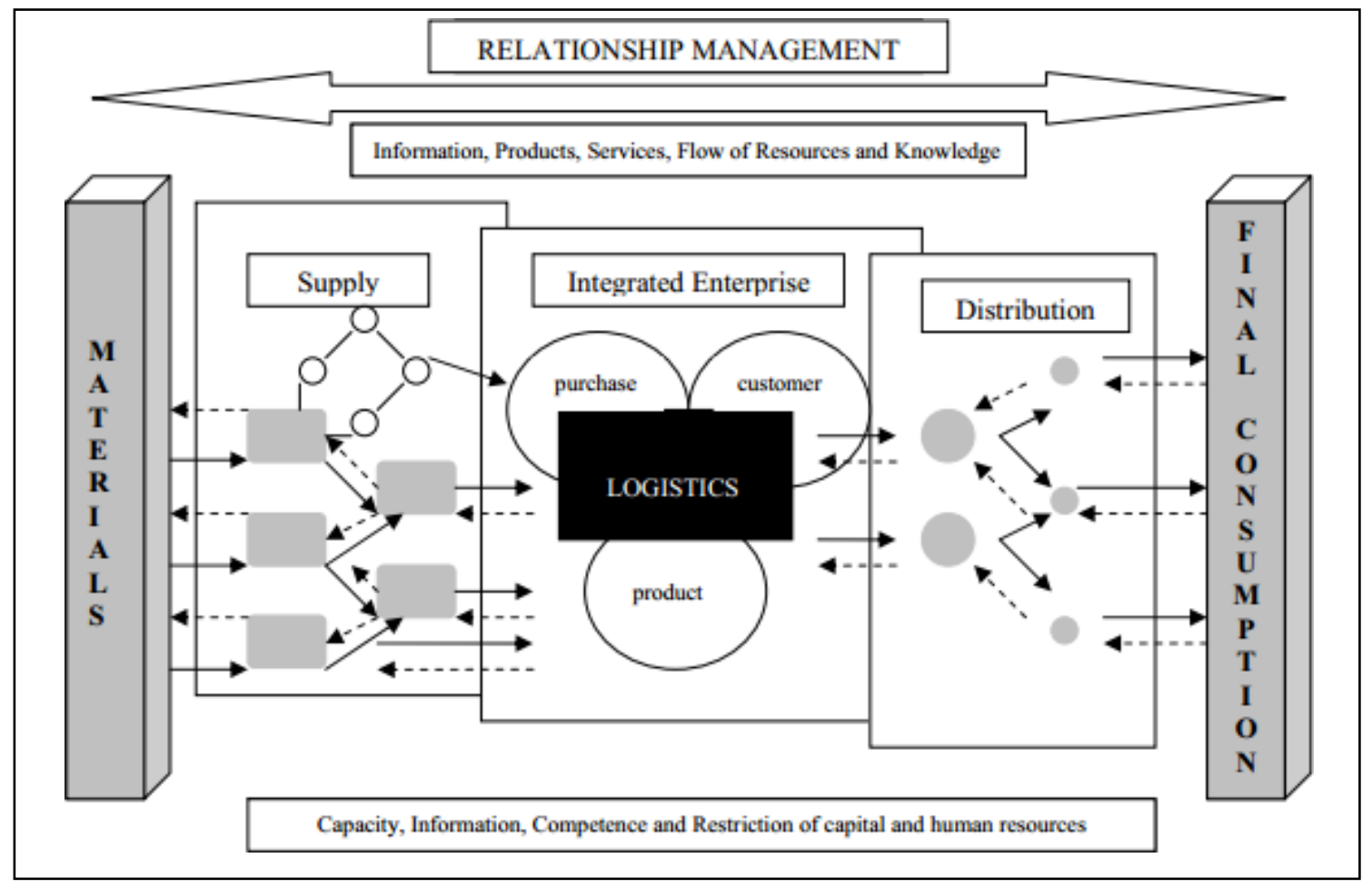

Figure 3: General Supply Chain Model. Source: Adapted from Bowersox et al. (2014). 
The importance of KM in SCM is understood by Rodríguez-Enríquez et al. (2016) when they stated that the efficient use of knowledge is fundamental for the survival and success of companies in globalized competitive markets, KM systems have become an essential tool for the SCM. The importance of knowledge sharing depends on its strong potential for solving problems and improving organizational performance, decision making and innovation.

Supply Chain Management uses several business and company processes that are relevant to customer service: order fulfillment, customer service management and product development, so if an employee retires or leaves the organization, your knowledge and experience (transcendental knowledge) will be present in the knowledge database in the form of information, allowing that, if another employee replaces him, he will be able to continue from where the latter left his job.

Innovation today is synonymous with progress and modernity in all areas, passing through the social sphere, through the educational system, to the economic sphere of science and economics, seeking new solutions that contribute to the competitive advantage in the market and, thus, raise the level of the economy and social development, guaranteeing a high quality of life, according to Witkowski (2017).

Ilie-Zudor et al. (2014) cite that in view of the amount and extent of the information, modern artificial intelligence methods can provide a substantial advantage for their abilities to collect and filter the available information, identify important phenomena and provide support to the decision.

The resulting shortage of material and delivery delays spread downstream of the Supply Chain, causing a ripple effect degrading performance in terms of revenue, service level and decreased productivity (Ivanov et al., 2014, Garvey et al., 2015, Dolgui et al., 2018, Dolgui et al., 2020, Li and Zobel, 2020).

Ivanov (2020) is more incisive in stating that epidemic outbreaks represent a special case of supply chain risks, and that this chain is distinctly characterized by three components. (i) the existence of a long-term interruption and its unpredictability; (ii) the simultaneous propagation of disruptions in the supply chain (ie, the cascade effect) and the spread of epidemic outbreaks in the population (eg, pandemic propagation) and (iii) simultaneous interruptions in supply, demand and logistical infrastructure .

And he goes on to state that "unlike other outbreaks with the risk of interruption, epidemic outbreaks start out small, but increase rapidly and spread across many geographic regions. Recent examples include SARS, MERS, Ebola, swine flu and, more recently, coronavirus (COVID-19 / SARS-CoV-2)" (Ivanov, 2020).

In their study, Araz et al., (2020) report that the current outbreak of the coronavirus (COVID-19) with regard to the logistics function, is "breaking many global supply chains". This statement can be corroborated by the report by (Fortune, 2020) which mentions that, "because they are lean and globalized in structures, the supply chains of many companies have become specifically prone to epidemic outbreaks". And they continues, reporting that $94 \%$ of the companies listed on the Fortune 1000 reported having had interruptions in their supply chain due to the coronavirus.

In conjunction with the logistical application, being used to support actions, mapping of the main locations to be served, routing of paths, etc., is the Geographic Information System (GIS).

"Currently, and for a long time to come, GIS development must be strengthened to form a data-driven system for rapid knowledge acquisition, which means that GIS should be used to reinforce the parameterization of the social operation of models and methods, especially when supporting social management". (Zhou et al., 2020).

The GEOeduc journal highlights that

"Geographic Information Systems are widely used to combat the spread of disease. They were even used at the time of the Ebola epidemic, in 2014. The GIS technology is responsible for grouping and crossing official information with geographical inputs". (Costa, 2020).

Zhou et al., (2020) point out ten challenges in the use of GIS with big data in space-time. Among these, one of the challenges is the assessment of the risk of material supply and 
transportation, which, in fact, impacts local, regional, national and, as the case may be, global logistics. The researchers then cite that "a stable and efficient national supply and transport system provides important support for successful epidemic prevention and control. We integrate several data sets, such as provincial epidemic data". Another challenge mentioned was the dynamic spatial balance of supply and demand for medical resources and they mention that

The spatial distribution of medical resources is generally balanced according to factors such as population density, but the lack of space, even with the outbreak of the epidemic and its rapid development, results in a space-time imbalance in the supply and demand of medical resources. In this case, the key to the prevention and control of epidemics is knowledge of the space-time dynamics of the supply and demand for medical resources to optimize the allocation of materials. (Zhou et al., 2020).

Under a more advanced connotation, Tachizawa et al. (2015) analyze the connections between smart cities and SCM, using a supply network perspective. For this, they propose an integration framework based on a bidirectional link between smart cities and large networks of data and supplies, where they communicate in a two-way manner. Flowing in this same line, Gnimpieba et al. (2015) approach that, with the advent of the internet of things (IoT) and cloud computing, we have been given a new approach, allowing us to collect, transfer, store and share information about the logistical flow for better cooperation and interoperability between partners supply chain, facilitating the dissemination of information on logistical flows of traceability, collaboration and interoperability between different actors in the supply chain.

\section{RESEARCH METHODOLOGY}

This article uses the methodology of bibliographic research of authors and their understanding of the subjects of KM, SCM and Health Logistics in times of pandemic. Research was carried out in order to seek an inter-relationship between the themes. Scopus, Emerald, Science Direct, Google Scholar databases were used, as well as books and magazines that could assist in obtaining knowledge to carry out the activity.

The bibliographic review is inserted in a context of integrative review as it allows the researcher to compare the problems that he wants to appreciate and, at the same time, authorizes him to draw a logical panorama in the entire development of scientific production.

\section{RESEARCH ANALYSIS}

KM presents itself as an important tool for storage and knowledge. In a globalized and accelerated world, the need for well-parameterized information means for the control, treatment, storage and availability of the correct knowledge, at the right time, is shared with the people who need it. Everyone, at some point, will lack the knowledge to produce their work and differentiate themselves in the face of adversities that are imposed daily by the modern world. Think of a large database, properly organized and having information fed by different types of actors, such as researchers, business, non-governmental organizations, governments, universities, etc. This was all coordinated by a team that would take care of the organization of the knowledge trees, carry out the mediations, filter the inconsistent data or without due added value, etc.

Understanding this whole process using the network perspective is fundamental for us to have a holistic view of the entire operating environment. In a globalized world there is no way to perceive the facts in a compartmentalized way, but in a collective and collaborative way.

Considering an environment immersed in a pandemic, we will certainly be talking about several collapsed systems. In governments and companies looking for a solution based on a series of mismatched and, often, supra or oversized information. 
Under these conditions, obtaining the correct information so that decisions are simple, efficient and logical is an enormous competitive advantage. The urgency to acquire effective knowledge can dictate the difference between who lives and who dies.

History has always been a source of knowledge and we are told of actions that went right or wrong, so resorting to memories of successful events can shorten decision making. Hence, once again the existence of existing knowledge repositories is effective.

When assessing the supply chain situation when pandemic events occur, we understand that the risks arising from a pandemic have a strong and immediate impact on the project structure of a supply chain network, as some some factories, suppliers and distribution centers in addition to forms of transport become temporarily unavailable. As we saw, the resulting shortage of material and delays in delivery are propagating downstream of the supply chain, resulting in a ripple effect degrading performance in terms of revenue, service level and decreased productivity, representing high risk for the supply chain due to problems caused by the generalized infection of the population that generates high demand in various inputs, which can generate chaos and the occurence of interruption and ruptures in logistics channels.

As support for logistical operations, the use of Geographic Information Systems (GIS) grows in importance, being used in the mapping of the main locations to be served, routing of deliveries, mapping of areas with a high concentration of cases, in order to provide planning deliveries to certain pre-established locations, outside the pandemic region, providing protection to those involved in the logistics process. In this way, the modalities of lockers, small advanced distribution centers, last mile, crossdocking, picking, pick up in store, or even delivery could be used to make the final route, from the delivery points outside the affected region to the final destination. In addition, it allows spatial vision, allowing planning for the allocation of materials according to the needs of the region.

In Figure 4 we have an informational flow model that demonstrates how knowledge management and supply chain management have similar flows. It is a simple process that, in short, makes us realize that, in both processes, logistics and knowledge, there is, initially, an entry very well understood as being an input, or raw data. During processing, the transformation actually takes place. These procedures are sequenced gradually. However, there is nothing to prevent a return to the previous phase in order to correct or improve the processes until the final availability of the knowledge or product, which will be something of recognized value for the final consumer. We understand that the consumer can be understood as any person who uses that product or knowledge to add value. Finally, there is always feedback from the system, where the processes can be reviewed based on the demand perceived by the end user / consumer, or even during the phases that occurred during the processes.

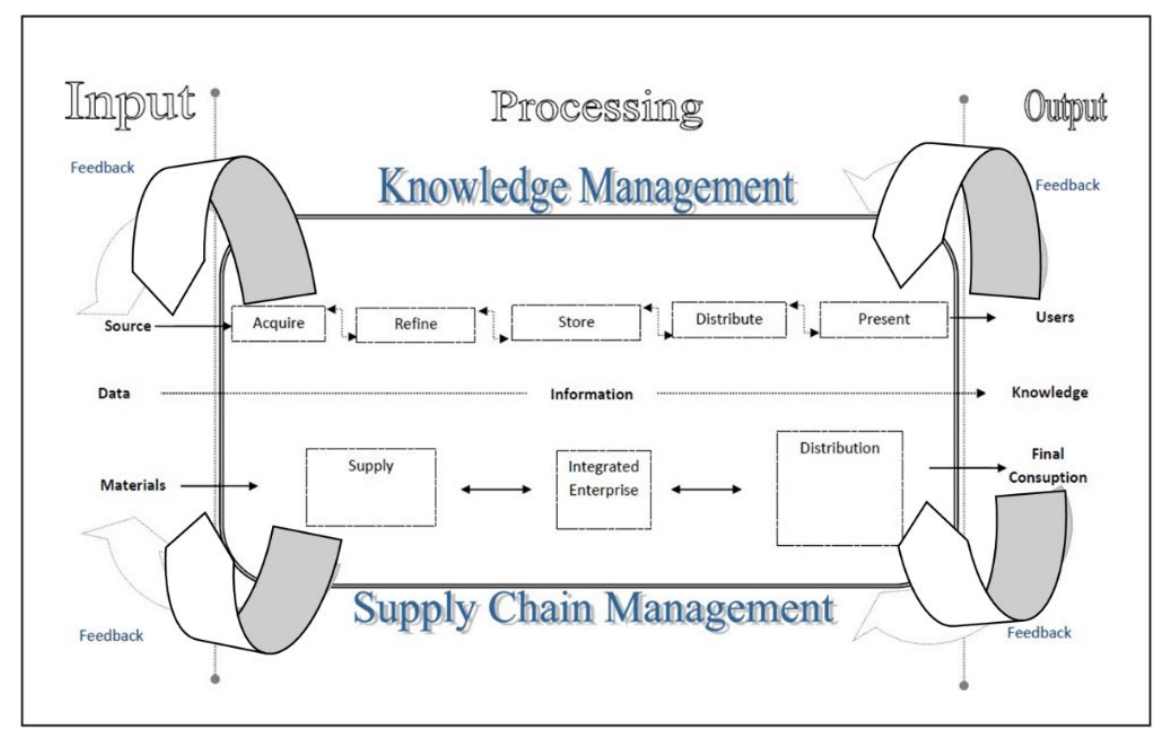

Figure 4: KM/SCM Information Flow Model 
Source: The autor himself.

As already mentioned, in a globalized world, inputs are not produced only in a specific country, causing input dependence to occur in the consumer goods manufacturing. This situation was evidenced in the current pandemic when several companies had difficulty in continuing their production chain of alcohol-gel, masks and respirators.

Bringing this model to a crisis environment overtaken by a pandemic, and based on the flows presented in Figure 4, we could assume that if there were studies or information stored in the KM process, the person responsible for the productive process (user) could obtain this knowledge and act at the input of the process (input) modifying the types, places or forms for the acquisition of the inputs, although eventually they could increase the manufacturing costs, the production could be preserved and would meet the emergency demand.

Likewise, companies that have adopted new techniques, inputs and processes, that had to reinvent themselves by modifying their current processes, could make their best practices available in the environment. In this way, knowledge could be shared and, obviously, improved with the proposition of the other users of the system.

It should be noted that there are several ways to share knowledge without hiding or leaking strategic and permitted information. The objective of knowledge management in some way is to encourage this practice, but rather, to allow that, within a "Win X Win" strategy, everyone uses sharing as best practices and an evolution in procedures, techniques and actions, allowing the continued study of these routines.

\section{CONCLUSION}

Understanding KM as a great knowledge transformer, seeking to attend in an orderly and qualified manner, the demands presented by people and/or their organizations is fundamental to understand the broad information-collaborative process in which it is immersed. Due to globalization and, because we are in the information age, we live immersed in deluge of data that make it difficult to acquire the correct content needed by each one to better carry out their activities. In order for all this knowledge to circulate, it is essential that your flows are properly parameterized and efficiently managed.

Walking in the same direction efficiently, SCM aims to serve its client, carrying out its steps through very well-coordinated flows and procedures, with the need for any knowledge to be available to meet the demands.

Adding to the logistical function the factors arising in the event of a pandemic, the supply chain ends up being overloaded in its mission of transporting production, just as it suffers from the lack of inputs to complete factory demands. As we saw during the analysis, the resulting material scarcity and delivery delays spread downstream the Supply Chain, causing a ripple effect degrading performance in terms of revenue, service level and decreased productivity.

The use of the geographic information system has been widely used in production planning and execution, and can be an excellent competitive advantage combined with other tools in order to allow a wide spectrum useb by the execution methods and how to use the logistical means.

This work sought to study how knowledge management can help supply chain management in planning, studying, acting and proposing new ways of solving problems, especially in times of crisis where the normality of actions ends up being compromised.

\section{REFERENCES}

Al-Ghamdi, H.A.K. and Al-Ghamdi, A.A.K. (2015), "The role of virtual communities of practice in knowledge management using Web 2.0. Procedia Computer Science", ICCMIT, Vol. 2015, No. 65, pp. 406-11.

Araz, O.M., Choi, T.-M., Olson, D.L. et al. (2020), "Data analytics for operational risk management", Decision Sciences 
Bowersox, D.J., Closs, D.J., Cooper, M.B. et al. (2014), Gestão Logística da Cadeia de Suprimentos, $4^{\mathrm{a}}$ ed., AMGH Editora Ltda, São Paulo.

Brasil (2020a). Ministério da Saúde, Portaria n 188, de 3 de fevereiro de 2020. Brasília, DF.

Brasil, Agência Nacional de Transportes Aquáticos (2020b), "Início: Importante Coronavírus", available at: http://portal.antaq.gov.br/index.php/importante-coronavirus/ (accessed 15 May 2020).

Calvo Mora, A., Navarro-Garcia, A. and Periañez-Cristobal, R. (2015), "Project management and key knowledge to improve business results through the EFQM excellence model", International Journal of Project Management, Vol. 33, No. 8, pp. 1638-51. http://dx.doi.org/10.1016/j.ijproman.2015.01.010.

Carvalho, F.C.A. (2012), Gestão do Conhecimento, Pearson, São Paulo.

Chang, C.L. and Lin, T.C. (2015), "The role of organizational culture in the knowledge management process", Journal of Knowledge Management, Vol. 19, No. 3, pp. 433-55. http://dx.doi.org/10.1108/JKM08-2014-0353.

Choo, C.W. (2006), A organização do conhecimento: como as organizações usam a informação para criar significado, construir conhecimento e tomar decisões, $2^{\text {a }}$ ed., Editora Senac, São Paulo.

Dalkir, K. (2017), Knowledge management in theory and practice, $3^{\mathrm{a}}$ ed., MIT Press, Cambridge, MA.

Dolgui, A., Ivanov, D. and Rozhkov, M. (2020), "Does the ripple effect influence the bullwhip effect? An integrated analysis of structural and operational dynamics in the supply chain", International Journal of Production Research, Vol. 58, No. 5, pp. 1285-301. http://dx.doi.org/10.1080/00207543.2019.1627438.

Dolgui, A., Ivanov, D. and Sokolov, B. (2018), "Ripple effect in the supply chain: An analysis and recent literature", International Journal of Production Research, Vol. 56, No. 1-2, pp. 414-30. http://dx.doi.org/10.1080/00207543.2017.1387680.

Fortune (2020), "Finance. Fortune 1000. 94\% of the Fortune 1000 are seeing coronavirus supply chain disruptions", available at: https://fortune.com/2020/02/21/fortune-1000-coronavirus-china-supplychain-impact/ (accessed 15 May 2020).

Garvey, M.D., Carnovale, S. and Yeniyurt, S. (2015), "An analytical framework for supply network risk propagation: A Bayesian network approach", European Journal of Operational Research, Vol. 243, No. 2, pp. 618-27. http://dx.doi.org/10.1016/j.ejor.2014.10.034.

Costa, N. (2020), "Coronavírus e SIG: Como a informação geográfica pode ajudar?", Geoeduc, 17 Março. available at: http://geoeduc.com/2020/03/17/coronavirus-sig-como-pode-ajudar/ (accessed 15 May 2020).

Gnimpieba, Z.D.R., Nait-Sidi-Moh, A., Durand, D. et al. (2015), "Using Internet of Things technologies for a collaborative supply chain: Application to tracking of pallets and containers", Procedia Computer Science, Vol. 56, No. 1, pp. 550-7. http://dx.doi.org/10.1016/j.procs.2015.07.251.

Ilie-Zudor, E., Kemény, Z., Ekárt, A. et al. (2014), "A solution for information management in logistics operations of modern manufacturing chains", Procedia CIRP, Vol. 25, pp. 337-344.

Ivanov, D., Sokolov, B. and Dolgui, A. (2014), "The Ripple effect in supply chains: trade-off 'efficiencyflexibility-resilience' in disruption management", International Journal of Production Research, Vol. 52, No. 7, pp. 2154-72. http://dx.doi.org/10.1080/00207543.2013.858836.

Ivanov, D. (2020), "Predicting the impacts of epidemic outbreaks on global supply chains: A simulation-based analysis on the coronavirus outbreak (COVID-19/SARS-CoV-2) case", Transportation Research Part E, Logistics and Transportation Review, Vol. 136, pp. 101922. http://dx.doi.org/10.1016/j.tre.2020.101922. PMid:32288597.

Jakobsone, A., Cakula, S. and Florea, M. (2017), "Modelling of Knowledge Sharing for the Provision of Sustainable Cooperation between Adult Educational Institutions and Enterprises", Procedia Computer Science, Vol. 104, pp. 160-5. http://dx.doi.org/10.1016/j.procs.2017.01.095.

Johansson, T., Moehler, R.C. and Vahidi, R. (2013), "Knowledge Sharing Strategies for Project Knowledge Management in the Automotive Sector", Physics Procedia, Vol. 74, No. 74, pp. 295-304.

Krumina, I., Krumins, G. and Rozentale, S.V. (2015), "Region of Latvia: Knowledge Management in Micro Enterprises", Procedia: Social and Behavioral Sciences, Vol. 213, pp. 781-6. http://dx.doi.org/10.1016/j.sbspro.2015.11.475.

Li, Y. and Zobel, C.W. (2020), "Exploring supply chain network resilience in the presence of the ripple effect", International Journal of Production Economics, Vol. 228, pp. 107693. http://dx.doi.org/10.1016/j.ijpe.2020.107693. 
Liberona, D. and Ruiz, M. (2013), "Análisis de la implementación de programas de gestión del conocimiento en las empresas chilenas", Estudios Gerenciales, Vol. 29, No. 127, pp. 151-60. http://dx.doi.org/10.1016/j.estger.2013.05.003.

Machado Neto, N.R. (1998), "Gestão de conhecimento como diferencial competitivo", in Seminário Gerenciamento da Informação no Setor Público e Privado, 4, 1998, Linker, Brasília.

Meyer, M. and Zack, M. (1996), "The design and implementation of information products", Sloan Management Review, Vol. 37, No. 3, pp. 43-59.

Mylonakou-Keke, I. (2012), "Social and Emotional Education Through Sociopedagogical Practices", Procedia - Social and Behavioral Sciences, Vol. 69, pp. 169-176.

Rodríguez-Enríquez, C.A., Alor-Hernández, G., Mejia-Miranda, J. et al. (2016), "Supply chain knowledge management supported by a simple knowledge organization system", Electronic Commerce Research and Applications, Vol. 19, pp. 1-18. http://dx.doi.org/10.1016/j.elerap.2016.06.004.

Tachizawa, E.M., Alvarez-Gil, M.J. and Montes-Sancho, M.J. (2015), "How “smart cities" will change supply chain management", Supply Chain Management, Vol. 20, No. 3, pp. 237-48. http://dx.doi.org/10.1108/SCM-03-2014-0108.

Terzieva, M. (2014), "Project Knowledge Management: how organization learn from experience", Procedia Technology, Vol. 16, pp. 1086-95. http://dx.doi.org/10.1016/j.protcy.2014.10.123.

Trejo, J.M., Gutiérrez, J.S. and Guzman, G. (2016), "The customer knowledge management and innovation", Contaduría y Administración, Vol. 61, No. 3, pp. 456-77. http://dx.doi.org/10.1016/j.cya.2015.11.011.

United Nations (2020), "United Nations Departament of Economic and Social Affairs Statistics. UM COVID-19 Data Hub", available at: https://covid-19-data.unstatshub.org/ (accessed 15 May 2020).

Witkowski, K. (2017), "Internet of Things, Big Data, Industry 4.0 - Innovative solutions in logistics and supply chains management", Procedia Engineering, Vol. 100, No. 182, pp. 763-9. http://dx.doi.org/10.1016/j.proeng.2017.03.197.

Zhou, C., Su, S., Pei, T. et al. (2020), "COVID-19: Challenges to GIS with Big Data", Geography and Sustainability, Vol. 1, No. 1, pp. 77-7. https://doi.org/10.1016/j.geosus.2020.03.005/

Authors contributions: Carlos Alberto Schettini Pinto conducted all the parts of this research. 